7.038.6:821.111(71).09-311.9 Gibson W. 82.02:007: [821.111(71).09-311.9 Gibson W.

81'42: 821.111(71).09-311.9 Gibson W. https://doi.org/10.18485/asec_sacs.2021.9.ch23

\author{
Mladen M. Jakovljević \\ University of Priština in Kosovska Mitrovica, Serbia
}

Mirjana N. Lončar-Vujnović ${ }^{* *}$

University of Priština in Kosovska Mitrovica, Serbia

\title{
WILLIAM GIBSON'S FICTIONAL WORLDS: TO VIRTUAL EXISTENCE AND BACK AGAIN (THERE) ${ }^{1}$
}

\begin{abstract}
The postmodernist literary reflections of transformation and the integration of knowledge, power, information and information technologies, and mercantilization of all aspects of reality in highly developed, commodified societies of the Sprawl trilogy made William Gibson one of the pioneers of the cyberpunk subgenre of science fiction. Although his later novels Pattern Recognition and The Peripheral do not belong to the same subgenre, they tap into the ideas explored in his cyberpunk visions of computerized space, prosthetic aids, post-industrial and post-humanist tendencies emerging as a reaction to the integration of body, mind and technology, and the overall virtualization of reality.

Not only does the seeming of otherness of the post-catastrophic technological cultures in these novels destabilize the idea of unique reality and linear time, but the technological

*mladen.jakovljevic@pr.ac.rs

**mirjana.loncar.vujnovic@pr.ac.rs

1 The paper is the result of research conducted within project no. OI 178019 "Translation in the System of Comparative Studies of National and Foreign Literatures and Cultures", funded by the Ministry of Education, Science and Technological Development of the Republic of Serbia.
\end{abstract}


impact on perception in visually oriented consumer societies blurs the boundaries between the virtual and the real, and makes them conspicuously fluid.

\section{Keywords}

virtual worlds; reality; cyberspace; science fiction; cyberpunk.

American-Canadian science fiction writer William Gibson started writing while he was a student at the University of British Columbia. At the beginning of his career his attitude to science fiction was similar to that of the 1960's New Wave SF's resentment towards the exhausted and already repetitive genre fiction, which he illustratively described as "a viable, but essentially derelict form of popular art" (No Maps for These Territories 27:40-27:50). In an endeavour to write something different from what the genre most commonly offered, Gibson dug into cybernetics, bioengineering, and, most importantly, into computer-generated realities, which had been ignored or insufficiently explored in literature. While conquering this new territory he pioneered the cyberpunk subgenre. It forecasted the development of the Internet and its tremendous impact on human lives, and it brought about the cultural revolution that exceeded the boundaries of literature, while affecting the culture on a wider scale. Gibson's unique literary style and the powerful metaphor of cyberspace brought him almost immediate recognition and high praise. The term cyberspace, which Gibson coined and first used in his story "Burning Chrome" to denote the "nonspace of the simulation matrix, the electronic consensus-hallucination that facilitates the handling and exchange of massive quantities of data" (Gibson 2003a: 181) is his greatest contribution to the genre that earned him the titles of the noir prophet of cyberpunk and the prophet of the information age.

Clearer shapes of the computer generated "space" emerge with his ground-breaking cyberpunk novel Neuromancer (1984) whose worlds, both virtual and physical, ${ }^{2}$ demonstrate how and why information equals power. Information, according to Gibson, is "the dominant scientific metaphor of our age", which "we need to face" and "try to understand what it means" (McCaffery 1990: 139). Cyberpunk owes its creation to the visionary attempts aimed at understanding the meanings and potentials of information, within the context of the breakdown of distinctions among cultures, genres, styles, and forms of artistic expression. This breakdown, or "cultural mongrelization" as described by Gibson in an interview, "seems to be what postmodernism is all about" (McCaffery 1991: 132). Cyberpunk, according to McHale, is the result of the "feedback loop" between science fiction and postmodernist fiction - it is science fiction that "derives certain of its elements from postmodernist mainstream fiction which

2 The term "physical world" will be used in this paper to denote objective reality of the material world. 
itself has, in turn, already been 'science-fictionalized' to some greater or lesser degree" (McHale 1992: 228-229). Cyberpunk most effectively concretizes the metaphors of postmodernist fiction in cyberspace, "a literary metaphor of very considerable brilliance" (Clute 2003: 71) denoting a "plastic (i.e. wholly malleable) mental landscape that derives from the new possibilities of computer graphics" (Disch 2005: 144).

In Neuromancer, and in his other cyberpunk novels, Gibson's focus is on computer technology as a metaphor of human memory.

On the most basic level, computers in my books are simply a metaphor for human memory: I'm interested in the hows and whys of memory, the ways it defines who and what we are, in how easily memory is subject to revision. (McCaffery 1990: 136) ${ }^{3}$

Gibson found the inspiration for the mental landscapes of cyberspace in video arcades, when he saw children who "clearly believed in the space games projected"; what is more, everyone he knew, who worked with computers believed that there was "some kind of actual space behind the screen, someplace you can't see but you know is there" (McCaffery 1990: 138). This belief in the projected space gave shape to a radically different idea of reality and space, and allowed for a range of exciting possibilities for their construction by using computer technologies.

Cyberpunk blends the present with the future, while interlinking body and mind with technology, projected into cyberspace, described in Neuromancer as

a consensual hallucination experienced daily by billions of legitimate operators, in every nation, by children being taught mathematical concepts... A graphic representation of data abstracted from the banks of every computer in the human system. Unthinkable complexity. Lines of light ranged in the nonspace of the mind, clusters and constellations of data. Like city lights, receding... (Gibson 1995: 67)

Cyberspace has built up a powerful image of virtual worlds, which are often considered to be a product of the modern age; however, "humans have craved and crafted virtual world experiences from the dawn of artistic and linguistic expression" (Damer \& Hinrichs 2014: 18). Virtual worlds as separate, distant places or as different, interconnected realities coexisted in "ancient myths, literature, and art as they coexist in contemporary conceptualizations of digital

3 The attempts to discover how memory is easily revised, and resulting considerations of possible outcomes of such a process, make his fiction if not similar to Philip K. Dick's literary efforts aimed to explore the relationships between reality and perception, then at least closely related to them, although Gibson explicitly denied any influence of Dick's fiction on his own. (Gibson 2003c; Gibson 2003d) 
technologies" (Bittarello 2014: 86). The concept of an avatar originates in mythology, where it represents an embodiment of a deity's essence by which it descends to visit and experience the material world. In a technological sense, it is not only "a mechanism to interact with the virtual environment" but "an extension of the self" (Scarborough \& Bailenson 2014: 135). As a reversed reflection of the concept of divine creation, the technological avatar becomes a means to experience the non-material world created by man.

Virtual worlds could be regarded as an integral part, or an extension of the physical world, so their creation, the process of diffusion, and eventual substitution of the physical with the virtual, as foreshadowed in cyberpunk fiction, seem to constitute a logical, even natural component of human creativity, capabilities, experience, and existence.

The adjective "virtual" in the compounds "virtual reality" and "virtual world" alludes to artificiality and, more often, to illusional quality. However, Gibson's fiction demonstrates how this illusional quality is annulled by gradual dissolvement of the differences and boundaries between the physical reality and the constructed worlds in the process of virtualization of reality, aimed at escaping the process of entropic decay of the material world that inevitably leads to deterioration, destruction and death.

Gibson has every right to consider himself a realist.

My SF is realistic in that I write about what I see around me. That's why SF's role isn't central to my work. My fiction amplifies and distorts my impressions of the world, however strange that world may be. (McCaffery 1990: 142)

Gibson's fictionalized impressions of the world amplify numerous dilemmas - political, philosophical, moral, and cultural - of the post-industrial and post-human societies, of commodification, of genetic and bio-engineering, of integration of body and technology/mental and virtual/ physical and synthetic realities, all of which have made it increasingly difficult to understand the world around, the pace of changes that take place in it and affect it, as well as where such changes lead to.

I think we live in an incomprehensible present. And what I'm actually trying to do is illuminate the moment, and... and make the moment accessible. I'm not even really trying to explain the moment. I'm just trying to... trying to make it accessible. (No Maps for These Territories 1:00:10-1:00:30)

Gibson's statement that his "feelings about technology are totally ambivalent", and that it seems "to be the only way to relate to what's happening today" (McCaffery 1990: 140), reveals that he is neither a technophile nor a technophobe. His fiction is an unbiased demonstration of the capabilities of technology, of its 
advantages and disadvantages, of its presence, use, and likely outcomes of its development. In and with his fiction, while making the world of computers and the mental landscapes of their graphics accessible, Gibson makes the world of everyday reality, with its profound and often confusing technologically induced metamorphoses, more accessible as well.

Gibson's fictional worlds are literary reflections of a range of transformations affecting the world - those expected to occur in the future, and the ongoing ones as well. Through familiarization with otherness of the technological culture and its ubiquitous consumerism, his cyberpunk mindscapes, with their technologically altered landscapes, individuals and societies, demonstrate the process of evolution that starts with integration of human/natural/physical with technological/artificial/virtual, and ends with substitution of the former with the latter. It may seem that such evolution, ending in Gibson's first trilogy with the protagonists abandoning the physical world and their bodies for the virtual world, suggests the prevalence of the virtual over the physical. However, his latest literary exploits indicate that the solution might not be in substitution but in fusion, in which the differences between the opposites disappear.

In Gibson's concept of experiencing cyberspace one can recognize a theological dualism based on St. Augustine's notion of the eternal soul that is distinct from a mortal and earthly body understood through the notion of the original sin - one example, Gibson's description of Case's loss of ability to connect to cyberspace as a reflection of the Fall (Ess 2014: 685). The notion of the disembodied virtual space, which is clean, clear, and devoid of entropy and gomi that permeates the real world, makes cyberspace look like paradise regained, or (re) constructed. As noticed by Hayles, in the post-human, "there are no essential differences or absolute demarcations between bodily existence and computer simulation, cybernetic mechanism and biological organism, robot teleology and human goals" (Hayles 1999: 2-3). Technology acts as the mediator between body and mind - on the one hand, it enables their separation and coexistence in two planes of reality and, on the other hand, it connects the material and the spiritual, the physical body and the consciousness, creating thus the continuum consisting of mind, body and reality, with no clear-cut boundaries.

The physical world, littered with trash, "a rich amalgam of stale subway exhalations, ancient soot, and the carcinogenic tang of fresh plastics, all of it shot through with the carbon edge of illicit fossil fuels" (Gibson 1987: 114), seems to stand in sharp contrast to the "consensual hallucination" of cyberspace and its "bodiless exultation" (Gibson 1995: 12). In spite of the apparent differences between the two worlds, the lines between them are fuzzy. The nonspace of the mind, made of data organized into neon geometric shapes resembling cityscapes to which men can plug in like a piece of equipment, becomes "mankind's extended electronic nervous system" (Gibson 2003a: 181). In our physical 
world, the example of such fusion is the Internet, which Gibson called "a kind of global, prosthetic extension of human consciousness" (No Maps for These Territories 1:18:20-1:18:30).

Gibson's first trilogy showcases the technological immanence that can be viewed as a five-phase process of transition to the virtual that eventually culminates in discarded physical bodies:

1. implanting - body implants and prosthetics (such as retractable blades in Molly's fingers or Ratz's prosthetic arm);

2. passivization - constructed, artificial intelligence in an organic body (such as Armitage, or bodies rented for erotic services), and time spent in cyberspace and simstim, when the body remains passively jacked into a deck;

3. interface - points of contact between technology and body (such as microchip and data drive ports built in heads to upload data and gain access to information);

4. integration - built in bio-technological structures (such as a biochip in Angie's brain) working as cyberspace decks, providing access to cyberspace and allowing cyberspace entities to access the body;

5. substitution - the organic body is discarded and the mind is willingly transferred to the matrix. (Jakovljević 2012: 227-229)

Two decades later Pattern Recognition (2003) showed that the future caught up with Gibson. The 9/11 terrorist attacks that shook America and the world cast a shadow over the entire fictional reality of the novel, which is quite similar to the reader's physical world. As a result of the attacks the protagonist Cayce Pollard develops an unusual type of allergy that provokes anxiety and phobic reactions to trademarks and brand-name products, such as Michelin Man, Tommy Hilfiger and Louis Vuitton. Although seemingly unadapted to the reality teeming with brand names, as a "design-free zone" allergic to the extent that she has to remove the logos from her clothes, Cayce uses her specific intolerance to highly commercial brands to become a specialized freelance marketing consultant capable of predicting a brand's success in the market, in which information about or on the product becomes more valuable than the product itself.

The novel's reality appears markedly different from Gibson's cyberpunk fictional visions, and yet it features the remnants of the well-known cyberpunk paraphernalia. In addition to dangerous military software, prosthetics, bioengineering, computers, plastics, neon commercials, Japanese culture and urban landscapes permeated with debris, waste and brands, Pattern Recognition also emphasizes the importance of information and the potentials of its use on the 
Internet, which becomes the source of anonymous video clips strikingly similar to virtual cyberspace projections. Leather outfits and mirrorshades, the most graphic examples of cyberpunk iconography, are no longer important parts of the image but they remain present as visual reminders of information represented in electronic form. In Pattern Recognition the world outside America seems almost virtual - "[c] ]ars are reversed, left to right, inside; telephone handsets have a different weight, a different balance; the covers of paperbacks look like Australian money" (Gibson 2003b: 2-3). These and other numerous distinctions build the image of the "mirror-world" because they create the impression that Cayce sees only reflections of reality.

The moment of the terrorist attacks in America is the moment when the events previously reserved for the media reach across their boundaries and become part of reality. It is the moment when the known, familiar reality becomes lost, the past is erased, the present is reconfigured, and the future remains uncertain (Jakovljević 2013: 236).

"The future is there," Cayce hears herself say, "looking back at us. Trying to make sense of the fiction we will have become." (Gibson 2003b: 57)

The Peripheral, ${ }^{4}$ a seemingly futuristic story of multiple realities, confirms Gibson's statement that he does not write about the future but about the world he sees around him. The novel introduces the future that is looking back at the present, "the fiction that we will have become," in which reality shatters, becomes fragmented, and is split into two timelines, or stubs as they are called in the novel, one occurring before Jackpot, a catastrophic event that wiped out the majority of the population and changed the world forever, and the other after it. The first one is the reality of Flynne Fisher, a rural America with half-empty shopping malls, and the other is the reality of Wilf Netherton, the futuristic London of modified nature and advanced technology, the reality in which simulacra outnumber humans. The advanced technology in the form of peripherals, anthropomorphic drones or avatars, makes possible the contact between the stubs. The visit to another stub is not classical time travel as only information can travel back and forth. As explained, the server which allows this is perhaps in Shanghai, it has "something to do with quantum tunnelling" and the furthest point in time that one can go back to is 2023 (Gibson 2014: 39).

4 The novel could be the first in the series. A "sequel and a prequel" (Alter 2017) to this novel, titled Agency, imagines an alternate US in which Hilary Clinton won the presidential election. Originally, Agency was due out in January 2018 but the release date was postponed several times - first to the end of 2018, then to April 2019, then to September 2019, and it was finally released on January 21, 2020. 
Similarly to the Sprawl trilogy, The Peripheral depicts the achievements and anxieties of a technologically oriented culture. Gibson here remains equally ambivalent about technology that has remarkably powerful capacities both to destroy and (re)create, as confirmed in the second timeline whose destroyed world has been rebooted into a new technologically improved future. Technology in it is omnipresent, fully yet subtly integrated in bodies and the world, functioning more as augmented reality, which is equally disorienting to visitors as are Cayce's visits to the mirror-world. Perception through the peripheral makes it difficult to distinguish between the physical and the virtual. The mysterious server that enables visits to one stub from another makes the relations between the two time lines even fuzzier.

When Flynne visits the London of the future, thinking she is there to test a game where she is expected to dispel paparazzi round a skyscraper, she witnesses a bizarre murder of a girl who is literally eaten away by nanotechnology. Thinking it is a "kind of nanotech chainsaw fantasy" (Gibson 2014: 72), she believes that everything she sees is a virtual construct - the building, the copter she is in, the entire city. Later, when she returns to the same stub, she keeps looking for evidence that what she sees is not a programmed, virtual world.

The ontological status of the stubs is questionable for several reasons. As a means to visit and experience another reality, the peripheral fits in the third definition of the virtual offered by Adams (2014: 239) , according to which "the virtual can be understood as a system that permits spatially dispersed participants to interact in a way that would otherwise require proximity and face-to-face interaction." This function does not undermine the reality of any of the stubs. The visit to another world, or stub, could be the visit to a different point in time of the same world, or to another, alternate world since the information transfer creates the time fork, the "connection produces a fork in causality, the new branch causally unique" (Gibson 2014: 103).

What casts doubt on the reality of the visited stub is the fact that the experience is made possible with the server, which means that it could be an immersive multisensory virtual experience with the maximum level of reality. In other words, the world visited by Flynne could actually be a construct. If so, then it cannot be an alternate world. Jeff Malpas argues for the non-autonomy of the virtual claiming that the virtual as an alternative to the "nonvirtual" or the "everyday" world is a fundamentally mistaken concept since "the virtual is not autonomous with respect to the everyday, but is rather embodied within it, and an extension of it." According to Malpas the virtual and the everyday worlds

5 The first one is intangible architecture that supports and organizes interaction, and the second one sensory fragmentation (the use of one or two senses while suspending or separating the other senses). 
cannot be regarded as alternate universes since there is only one world, the everyday world, and the virtual is its part. As such, it is causally dependent on the everyday, and it does not offer release from the limitations of embodiment. Although the virtual is not a way out of the physical constraints, it "does enable an escape from the experiential constraints of the everyday" (Malpas 2008).

There is no final answer to the status of these words. Flynne's confusion of reality for the game echoes the arcade gaming origins of cyberspace. The stub, experienced through the peripheral, could either be a construct, or a newly discovered reality made accessible by technology, or both. And yet, the novel is not an example of the return to cyberpunk roots, although it shares with them two significant facets: reconfiguration of reality, or realities, and fuzzy boundaries between the virtual and the physical worlds.

The nature of technology and of the worlds it affects remain mysterious in Gibson's fiction, which should not be interpreted as an attempt to faithfully present how information technology works or how it will work in the future, not in Neuromancer, and certainly not in The Peripheral. The prime focus is on the implications that technology and information carry for technologically advanced societies - not necessarily for the future ones, but also for those in which the readers live.

According to Gibson, technology, and the media in particular, have grown to "a sort of prosthetic, extended nervous system for the last hundred years or so", which is why it is "very difficult to find "non-mediated' human beings" (No Maps for These Territories 10:10-10:48). Contemporary and emerging technologies such as virtual reality, simulation rides, video conferencing, HD, 3D and IMAX film technologies, are designed to create an illusion of a non-mediated experience, which leaves the impression of "real", "direct", "natural", "immediate", and a strong sense of presence (Lombard \& Ditton 2006). The experience in the virtual is defined by vividness, which is "the ability of a technology to produce a sensorially rich mediated environment" and by interactivity, which is "the degree to which users of a medium can influence the form or content of the mediated environment", including responses to "user input (responsiveness) and the ability of the user to respond to the environment (interaction)" (Scarborough \& Bailenson 2014: 134).

The avatar technology of the peripheral, as "the extension of the self", allows such a deep and convincing sense of presence, vividness, and interactivity of the experience that Flynne cannot distinguish between the construct and the real, so she believes that a mediated experience of the real world is a mediated experience of the virtual world. The peripheral-mediated sense of presence, vividness, and interactivity create the impression that stubs are not simulations, that they physically exist, but the fact that the experience is mediated harbours 
suspicion and creates an existential uncertainty, even anxiety as to the realness of the supposedly real worlds, on both sides of the Jackpot. The dilemma whether they are virtualizations of the real or actualizations of the virtual remains unresolved, which makes them similar to the worlds of fairies and spirits that co-exist and sometimes overlap with the physical reality (in fiction) - they are experienced, yet the evidence of their realness remains elusive.

The utopian-like promise of peace, advancement and prosperity is inextricably connected with the dystopian visions of the use, abuse and misuse of technology, and the resulting dangers, both possible and imminent. Technology can provide the means to experience dystopia "in relative safety", "to deal with terror or horror, from a safe place" (Hunter \& Mosco 2014: 728). However, the apparent safety of the virtual is brought into question with the disappearance of the boundaries between the worlds. Although Gibson's first "trilogy foreshadows the allure of the digital sublime" their protagonists "enter into cyberspace in search of the "wealth and power immanent in data" (Hunter \& Mosco 2014: 731, 732). The transfer of existence to a virtual utopia in Mona Lisa Overdrive could easily turn into a life-threatening experience, even a fatal one, in the world of chainsaw fantasies in which nanobots devour individuals, so Molly's statement that "There's dying, then there's dying" (Gibson 1989: 301) could start ringing differently.

Owing to "progressive embodiment", the process introduced by Biocca (1997) to define "the steadily advancing immersion of sensorimotor channels to computer interfaces through a tighter and more pervasive coupling of the body to interface sensors and displays," the functionalities of avatars and virtual technology in general provide an immersive experience with a steadily increasing level of reality of the virtual world that would eventually become the faithful technological translation of physical reality.

If a virtual world develops into an immersive, multisensory experience, with a level of reality that makes it indistinguishable from the physical world - when does it cease to be virtual? The answer may prove to be irrelevant. If being human implies the use of language, tools, and technology, then virtual worlds are an aspect of being human, its natural aspect and a logical extension of existence. In this sense, The Peripheral is the continuation of the path that earned Gibson the title of the father of cyberpunk. As announced in Neuromancer, information has the capacity to create realities and to affect their perception, while technology, owing to its capacities to store, convey and use information, develops the potential to erase the boundaries between realities, to transfer individuals from one reality to another, and to wipe out all differences between the physical landscape and the mental landscapes of computer graphics. 
With the virtual world and the physical world becoming a continuum, a logical step following the experience of immersion could be full absorption into the virtual. People have already become addicted to the virtual so the transition into it could be completed smoothly. Still, such a drastic move away from the physical existence is by no means essential, since the two worlds are not mutually exclusive and they can complement each other well. The achievements and anxieties of technologically shaped societies and the dissipating boundaries between virtual spaces, video-games and physical reality in William Gibson's (science) fiction show that the expected emancipation does not come with migration to the virtual and complete desertion of the physical world but through technological ruptures and fissures embedded in it, which is why William Gibson, the "noir prophet" of cyberpunk, can be said to have become the noir prophet of reality.

\section{WORKS CITED}

Alter, Alexandra. "Sci-Fi Writer William Gibson Reimagines the World After the 2016 Election." The New York Times, 25 April 2017. Online: https://www. nytimes.com/2017/04/25/books/sci-fi-writer-william-gibson-reimagines-theworld-after-the-2016-election.html [Accessed 1 May 2019].

Biocca, Frank. "The Cyborg's Dilemma: Progressive Embodiment in Virtual Environments." Journal of Computer-Mediated Communication, 3.2 (1997). DOI: 10.1111/j.1083-6101.1997.tb00070.x

Bittarello, Maria Beatrice. "Mythologies of Virtuality: 'Other Space' And 'Shared Dimension’ From Ancient Myths To Cyberspace.” In: Mark Grimshaw (Ed.). The Oxford Handbook of Virtuality. Oxford University Press (2014), 86-110.

Clute, John. "Science Fiction from 1980 to the present." In: James, Edward and Mendelsohn, Farah (Eds.). The Cambridge Companion to Science Fiction. Cambridge: Cambridge University Press, (2003), 64-78.

Damer Bruce and Hinrichs, Randy. "The Virtuality And Reality of Avatar Cyberspace.” In: Mark Grimshaw (Ed.). The Oxford Handbook of Virtuality. Oxford University Press (2014), 17-41.

Disch, Thomas M. On SF. The University of Michigan Press, 2005.

Ess, Charles M. "Ethics at the Boundaries of the Virtual." In: Mark Grimshaw (Ed.). The Oxford Handbook of Virtuality. Oxford University Press (2014), 683-967.

Gibson, William. Count Zero. New York: Ace Books, 1987.

Mona Lisa Overdrive. New York: Bantam, 1989.

Neuromancer. London: Voyager/HarperCollins Publishers, 1995. 
------- Burning Chrome. New York: Eos/HarperCollins Publishers, 2003a.

------ Pattern Recognition. New York: G. P. Putnam’s Sons, 2003b.

2003c. Blog entry (13 January 2003). http://blog.williamgibsonbooks. com/2003/01/page/2/ [Accessed in September 2010]

------ 2003d. Blog entry (28 January 2003). http://blog.williamgibsonbooks. com/2003/01/ [Accessed in September 2010]

------ The Peripheral. New York: Berkley, 2014.

Hayles, Katherine N. How We Became Posthuman: Virtual Bodies in Cybernetics, Literature, and Informatics. Chicago: The University of Chicago Press, 1999.

Hunter, Andrea and Mosco, Vincent. "Virtual Dystopia." In: Mark Grimshaw (Ed.). The Oxford Handbook of Virtuality. Oxford University Press (2014), 727-737.

Jakovljević, Mladen. "Kiberpank Vilijama Gibsona: od simulacije do stvarnosti." Zbornik radova Filozofskog fakulteta u Prištini, 43.1 (2013), 223-238.

Jakovljević, Mladen. "Paralelni svetovi: odnos postmoderne proze prema fantastičnoj i naučnofantastičnoj književnosti" (Unpublished doctoral dissertation). Novi Sad: Faculty of Philosophy, 2012.

Lombard, Matthew and Ditton, Theresa. "At the Heart of It All: The Concept of Presence." Journal of Computer Mediated Communication 3. 2. 1997 (2006). DOI: 10.1111/j.1083-6101.1997.tb00072.x

Malpas, Jeff. "The Non-Autonomy of the Virtual: Philosophical Reflections on Contemporary Virtuality." Ubiquity, 9. 19 (2008). https://ubiquity.acm.org/ article.cfm?id=1378359 [Accessed 1 May 2019].

McCaffery, Larry. Across the Wounded Galaxies: Interviews with Contemporary American Science Fiction Writers. Urbana, Chicago: University of Illinois Press, 1990.

McHale, Brian. Constructing Postmodernism. London, New York: Routledge, 1992.

Martin, Jean-Claude. "Emotions and Altered States Of Awareness: The Virtuality of Reality and the Reality of Virtuality." In: Mark Grimshaw (Ed.). The Oxford Handbook of Virtuality. Oxford University Press (2014), 162-172.

No Maps for These Territories. Dir. Mark Neale. DVD. Docurama Films, New Video Group. 2000.

Scarborough, James K. and Bailenson, Jeremy N. "Avatar Psychology.” In: Mark Grimshaw (Ed.). The Oxford Handbook of Virtuality. Oxford University Press (2014), 129-144. 